contains a number of interesting papers. The paper by de Haas and his co-workers on the attainment of very low temperatures by adiabatic magnetic changes is referred to in our Research Items (p. 181). Druyvesteyn describes experiments on the lowvoltage arc in sodium vapour. The absorption of the $D$ lines was measured in the arc and the reversal of the $D$ lines against a continuous source at variable temperature was observed. The results show that the number of excited sodium atoms is about 12 per cent of the number of the normal atoms, and that the number of $\mathrm{Na}+$ ions is several times the number of normal atoms. The theory of light emission in gaseous discharges is discussed by W. De Groot. Van Heel describes a quartz-fluorite combination lens which is achromatic and spherically connected. It is intended for focusing light on a thermocouple with unit magnification. P. Cohen Henriquez describes a micro-apparatus for determining the dipole moment of organic solutes. The apparatus may be used with a few milligrams of material. The ratio of the lithium isotopes has been determined by intensity measurements of the fine structure of the $\mathrm{Li}$ resonance line by Ornstein, Vreeswijk and Wolfsohn. Van Kreveld describes an empirical summation law for a photographic plate exposed to light of two or more colours, and Van der Pol and Weyers describe the approximations known as Tchebycheff polynomials. The papers are in English or German, and in some cases German papers are provided with an abstract in English.

\section{Recent Acquisitions at the British Museum (Natural History)}

Among the recentacquisitions at the Natural History Museum the Department of Zoology has received as a donation from Mrs. Charles Buckley and Mr. Godfrey R. Buckley the mounted head of a cow of the Chartley breed of cattle. Chartley Park was formed by enclosing about 1,000 acres of the forest of Needwood in the reign of Henry III, when a number of half-wild cattle, which then roamed throughout the district, were driven in and enclosed in the Park. Two important additions have recently been made to the beetle collections in the Department of Entomology, namely the Donisthorpe collection of British Coleoptera and an Australian collection purchased from Mr. W. du Boulay. The former contains upwards of 22,000 specimens, and is of especial interest in that it is accompanied by the most complete set in existence of the numerous British insects (mainly beetles) and other arthropods that live in association with ants and are known as myrmecophiles. The du Boulay collection, which numbers only 352 specimens, consists, however, entirely of beetles actually found inhabiting ants' nests in various parts of Australia by Mr. du Boulay over a period of sixteen years. Mr. R. E. Turner, working in South Africa, has collected and presented to the Museum some 8,000 insects of various kinds, principally small bees and wasps; and from the mountains of New Guinea Miss L. E. Cheesman has collected for the Museum upwards of 18,000 specimens. Miss M. Graves, M.P., has presented to the Geological
Department some portions of the egg-shell of a small horned dinosaur, Protoceratops andrewsi. The South Australian School of Mines and Industries has presented an end-slice of a large mass $(2,520 \mathrm{lb}$.$) of$ meteoric iron found in 1909 at Murnpeowie, South Australia, previously represented in the collection only by a cast of the whole mass.

\section{Sunday Lectures at the British Museum (Natural History)}

For the benefit of visitors to the Natural History Museum on Sunday afternoons who may wish for fuller information about the various branches of natural history than may be obtained by casual wandering through the galleries, the Trustees of the British Museum have arranged for two lectures each afternoon at 3 and 4.30 , to be given usually by a member of the scientific staff. Lectures illustrated by lantern slides will be given in the Board Room, and the remainder in one of the galleries. The opening lecture will be on Sunday, February 4, the lecturer being Capt. Guy Dollman, who will speak on the great game animals of Africa and will show a number of lantern slides. On succeeding Sundays lectures will be given by Dr. W. E. Swinton on earthquakes, Mr. Maurice Burton on seashore animals (both in the Board Room), and Mr. J. R. Norman on the Fish Gallery. Admission to the lectures is free.

THE Department of Botany of the Natural History Museum has received a bequest of the herbarium of the late Ashley H. Maude. The specimens are well mounted on about 5,000 sheets and are in good condition, contained in four cabinets. They are chiefly European but there are also collections from Algeria, Cape Colony and the Canary Islands. The Godman Trustees have presented 534 specimens of flowering plants collected by Mr. F, Ludlow and Capt. G. Sherriff in Bhutan. The area traversed is one which is not very well known botanically and as each 'number' comprises a good series of welldried plants the collection is of great value. A number of seeds were also collected, and these have been distributed. This year's collecting season in Nepal was ruined by the monsoon and consequently only fourteen specimens were collected by Prof. K. Sharma. These were presented to His Majesty the King and placed by him on loan in the Department of Botany. Although the number is small it includes several very important horticultural plants.

\section{Empire Museums and the Carnegie Corporation}

IT is gratifying to learn (from the December number of the Museums Journal) that the Carnegie Corporation has decided to grant substantial sums for the development of the museums of the Empire, following upon the Empire Survey of Museums, to which reference has been made in these notes. Already grants totalling 50,000 dollars have been made in Canada, and it has just been made known that similar sums have been set aside for South Africa, Australia and New Zealand. These will be administered by local committees. In addition to the 200,000 dollars thus earmarked, the Carnegie Corporation has also decided to appropriate 63,000 